\section{Analysis of Postdoctoral Training Outcomes That Broaden Participation in Science Careers}

\author{
Brian J. Rybarczyk, ${ }^{\ddagger *}$ Leslie Lerea, ${ }^{\dagger}$ Dawayne Whittington, ${ }^{\S}$ and Linda Dykstrall \\ ${ }^{\dagger}$ Graduate School, "Department of Biology, and "Department of Psychology and Neuroscience, \\ University of North Carolina at Chapel Hill, Chapel Hill, NC 27599; \$Strategic Evaluations, Durham, \\ NC 27707
}

\begin{abstract}
Postdoctoral training is an optimal time to expand research skills, develop independence, and shape career trajectories, making this training period important to study in the context of career development. Seeding Postdoctoral Innovators in Research and Education (SPIRE) is a training program that balances research, teaching, and professional development. This study examines the factors that promote the transition of postdocs into academic careers and increase diversity in science, technology, engineering, and mathematics. Data indicate that SPIRE scholars $(n=77)$ transition into faculty positions at three times the national average with a greater proportion of underrepresented racial minorities (URMs) and females represented among SPIRE scholars. Logistic regression models indicate that significant predictors are the intended career track at the start of the postdoctoral training and the number of publications. Factors necessary for successful transition are teaching experience as independent instructors, professional development opportunities, and the experience of balancing teaching with research. Scholars' continued commitment to increasing diversity in their faculty roles was demonstrated by their attainment of tenure-track positions at minority-serving institutions, continued mentorship of URMs, and engagement with diversity initiatives. These results suggest that a postdoctoral program structured to include research, teaching, and diversity inclusion facilitates attainment of desired academic positions with sustained impacts on broadening participation.
\end{abstract}

\section{INTRODUCTION}

The goal of ensuring that the scientific workforce reflects the changing demographics of the U.S. population has been a major concern for several decades (National Science and Technology Council, 2000; Building Engineering \& Science Talent, 2003). Broadening participation in science, technology, engineering, and mathematics (STEM) fields is crucial for the scientific research enterprise to remain innovative and competitive in the global economy (Hue et al., 2010; National Institute of General Medical Sciences [NIGMS], 2011). Broadening participation is defined as introducing underrepresented groups to academic science, with underrepresented groups including women, persons with disabilities, and ethnic and racial groups, including African Americans, Hispanics, Native Americans, Alaska Natives, and Pacific Islanders (National Science Foundation [NSF], 2016).

Many studies have examined supportive interventions to broaden participation in STEM fields during undergraduate education, factors that influence matriculation into graduate programs and subsequent transition into research careers (Austin et al., 2009; Fuhrmann et al., 2011; Gibbs and Griffin, 2013; McAlpine and Emmioglu, 2015). Research indicates that trainees' waning interest in pursuing academic research careers happens during graduate studies (Fuhrmann et al., 2011; Sauermann and Roach, 2012) and has led to concern about the current and future state of the scientific workforce in the United States, particularly with the disproportionately low numbers of underrepresented
Kenneth Gibbs, Monitoring Editor Submitted January 13, 2016; Revised April 27, 2016; Accepted May 2, 2016

CBE Life Sci Educ September 1, 2016 15:ar33 DOI: 10.1187/cbe.16-01-0032

*Address correspondence to: Brian J. Rybarczyk (brybar@unc.edu).

() 2016 B. J. Rybarczyk et al. CBE-Life Sciences Education @ 2016 The American Society for Cell Biology. This article is distributed by The American Society for Cell Biology under license from the author(s). It is available to the public under an Attribution-Noncommercial-Share Alike 3.0 Unported Creative Commons License (http://creativecommons.org/licenses/ by-nc-sa/3.0)

"ASCB®" and "The American Society for Cell Biology $\circledR^{\prime \prime}$ are registered trademarks of The American Society for Cell Biology. 
racial minorities (URMs) in STEM fields (National Science Board, 2007). Reasons for this waning interest in staying in science and pursuing academic careers are multifaceted and include negative perceptions of work-life balance, slow pace of research, and concerns surrounding typical responsibilities and stresses associated with the competitive nature of faculty careers such as grant writing and publishing (Fuhrmann et al., 2011).

Research productivity is the major focus of doctoral training in the sciences and continues into the postdoctoral stage; however, additional faculty career responsibilities such as teaching, mentoring, service, leadership, and outreach are not necessarily incorporated into training in graduate school. As future faculty, graduate students and postdoctoral scholars often recognize the need for a more holistic training experience in addition to research productivity in order to be competitive on the academic job market. To address this need, programs have been designed to aid in preparing future faculty with pedagogical training and related professional development opportunities aligned with the responsibilities of academic faculty careers. Preparing Future Faculty programs supported by the Council of Graduate Schools have been implemented at 300 institutions across the nation (www.preparing-faculty.org) with the mission of providing opportunities for graduate students, and to some extent postdoctoral scholars, to develop skills in balancing research, teaching, and service. The Center for the Integration of Research, Teaching, and Learning (www.cirtl.net) is a network of shared expertise, resources, and training opportunities for graduate students and postdoctoral scholars that supports their development as future faculty (Austin et al., 2009).

At the postdoctoral training stage, structured programs have been developed that assist with pedagogical skill development and academic professional development. For example, the Faculty Institutes for Reforming Science Teaching aims to increase postdoctoral scholars' use of more learner-centered teaching approaches in biology classrooms (Ebert-May et al., 2015). The National Institutes of Health (NIH)-supported Institutional Research and Academic Career Development Award (IRACDA), funded by the NIGMS Division of Training, Workforce Development, and Diversity, seeks to facilitate postdoctoral scholars' transition into research and teaching careers in academia through enhanced training in research, formal teaching experience, and the development of professional skills aligned with the professoriate. Outcomes for postdoctoral scholars from these training programs demonstrate that they are equally productive in their disciplinary research compared with postdoctoral scholars not involved in the program, even with the additional responsibilities of developing and teaching courses as independent instructors and engaging in professional development opportunities to expand critical academic career skills. Moreover, the additional training in teaching and professional development increases the success of program participants in obtaining academic positions (Holtzclaw et al., 2005; Hue et al., 2010; Rybarczyk et al., 2011).

The postdoctoral training experience is intended to enhance a scientist's research skills, professional development, and independence. There is a need for more research and reporting of postdoctoral scholars' experiences and career outcomes (Polka et al., 2015) that will assist with improving this training period and career planning for future trainees. The declining availability of tenure-track faculty positions at institutions across the country (Knapp et al., 2010; Cyranoski et al., 2011) has contributed to concerns about how trainees attain and transition into these types of positions. Reports have shown that an average $19.4 \%$ of all doctoral recipients across science, engineering, and health hold tenured and tenure-track faculty positions 3-5 yr after receipt of their degrees (NSF, 2016). In addition, and even more pronounced after the economic downturn of 2008, some view the postdoctoral time period as a holding pattern that does not have a defined timeline for postdoctoral scholars waiting for academic positions to become available (Powell, 2015).

Several factors are associated with transition into academic positions. Gibbs and colleagues showed that PhDs in the biomedical sciences expressed a decreased interest in academia overall and decreased interest in academic faculty careers based on gender, race, and ethnicity (Gibbs et al., 2014). Outcomes from an NIH-supported postdoctoral training program revealed that mentorship, support for career independence, and a sense of professional identity were key features that assisted the postdoctoral scholars' transition into their current career positions (Faupel-Badger et al., 2015). Some of the challenges with predicting and tracking career pathways include conflicting reports of the level of contribution of other factors to career decision making, such as the influence of mentors, availability of financial support, perception of self-success in careers, and availability of desired faculty positions (Sauermann and Roach, 2012; Gibbs et al., 2015). Others studies have identified factors such as 1) motivation for research careers, 2) self-efficacy in math/ science, 3) personal values, and 4) social identity that influence career trajectories in STEM (Lent et al., 1994; Byars-Winston et al., 2010, 2011; Garriott et al., 2013; Gibbs and Griffin, 2013).

Because the IRACDA programs are intended as support for future faculty development and broadening participation in STEM disciplines, these programs provide an ideal sample of postdoctoral scholars who desire to transition into academic careers. Thus, the purpose of the current study was to provide data about the outcomes of such a training program and address the following research questions: 1) What are predictors of career outcomes of postdoctoral scholars who pursue academic faculty careers? 2) What were the impacts of the 2008 economic downturn on their transition to academic positions? 3) Which aspects of a formal postdoctoral training program were most helpful in their transition to faculty positions and acclimation to faculty responsibilities early in their careers? 4) What measures provide insight into impacts for broadening participation in STEM?

\section{METHODS \\ Description of Program}

Seeding Postdoctoral Innovators in Research and Education (SPIRE) is one of 20 postdoctoral programs currently funded by the IRACDA program of the NIGMS Division of Training, Diversity, and Workforce Development. The overall goals of the IRACDA program are intended to support the development of a diverse group of postdoctoral scholars in research and contribute to the education and training of the next generation of scientists at partner institutions. SPIRE is a collaborative consortium between a research-intensive institution, the University of North Carolina at Chapel Hill (UNC Chapel Hill), and minority-serving institutions (MSIs) in North Carolina. The program 
has partnered with eight different MSIs since 1999: Elizabeth City State University, Fayetteville State University, Johnson C. Smith University, North Carolina A\&T State University, North Carolina Central University, Shaw University, University of North Carolina at Pembroke, and Winston-Salem State University. During the 3-yr fellowship, postdoctoral scholars develop research projects under the mentorship of faculty at UNC Chapel Hill and teach courses for two semesters at the partner institutions with an overall $75 \%$ time commitment to research and $25 \%$ commitment to pedagogical and professional development over the 3-yr fellowship. Full details of the structure of the program were published previously (Rybarczyk et al., 2011).

\section{Participants}

This study includes data from participants $(n=81)$ who were accepted into and entered the SPIRE program over a 15-yr period. Two scholars left the program within $1 \mathrm{yr}$ after their start dates, and two other scholars are continuing their postdoctoral training at the time of this article's submission after their $3 \mathrm{yr}$ of support, so their career outcomes were not included in the final analyses. Thus, career outcomes are reported for 77 scholars who participated in the program between 2000 and 2015. Solicitation for applications to the program was a nationwide effort, and applications were reviewed by select faculty from all institutions involved in the partnership. Selection criteria for entry into the program included publication record, interest in teaching, discipline of research, vision for postdoctoral research goals, and commitment to increasing diversity in STEM. The accepted scholars entered the program in cohorts to engage in common training opportunities and to contribute to the overall program community of scholars. The research areas of the scholars included biology, biochemistry, biomedical sciences, cell biology, chemistry, ecology, environmental sciences, genetics, psychology, and neuroscience, among others.

\section{Data Collection and Analysis}

Data were collected from several sources in collaboration with Strategic Evaluations (Durham, NC). While in the program, postdoctoral scholars provided productivity metrics from both graduate and postdoctoral training in the categories of publications, presentations, courses taught, students mentored, grants and awards received, job applications submitted, and career positions. These data were housed in a repository database, iBioSketch.com. For qualitative data collection, several steps were taken to obtain both confirming and disconfirming evidence. An independent, external evaluation team designed semistructured interview protocols composed of probes to elicit aspects of the program that were beneficial to the postdoctoral scholars' career development and probes that provided opportunities for them to share issues, challenges, and shortcomings of the program that failed to address their career development needs. Qualitative data were collected from individual and focus group interviews at the start, during, and after the training period. The interviews were conducted by phone, transcribed, and analyzed via Atlas.ti (Berlin, Germany) to assign thematic codes to the narrative data. Scholars' statements were coded with reference to their research progress, quality of mentoring provided, engagement with professional development opportunities, general program support, teaching development and readiness for classroom teaching, and readiness for career transition. All unique identifiers were masked from the responses before reports were shared with the administrative staff. Scholars who completed the program provided additional information via CVs, email surveys, and direct email correspondence. Ten scholars (80\% female, 10\% URM) who completed the program between 2012 and 2013 were interviewed 12-18 mo after starting their first faculty positions. The interview protocol included probes to determine the impacts of their postdoctoral training experiences in relation to their perceived readiness and confidence in fulfilling their current faculty responsibilities and probes for them to reflect on gaps in their preparation for their first faculty position and areas in which the program did not adequately prepare them.

The expected career outcomes of SPIRE scholars is an academic position that involves research and teaching, which can manifest in different proportions depending on the type of institution and responsibilities of the position. These ratios can include a range of institutions from primarily undergraduate institutions, which emphasize more teaching responsibilities, to research-intensive institutions, which emphasize research productivity in publications and grants but still may also require some level of teaching responsibilities. Thus, for logistic regression models, the dependent variable was defined as the actual career outcome of the postdoctoral scholars coded with dummy value: 1 = faculty position that includes teaching and research or $0=$ other type of position. These classifications were verified with interview data for each participant. Statements about a predicted career outcome were extracted from cover letters that were submitted by applicants who were accepted into and entered the program. These statements were coded using the same binary values above for the actual career outcome variable. Predictor variables used were coded as URM status ( $1=$ URM, $0=$ non-URM) and gender ( $1=$ female, $0=$ male). In some analyses, a more inclusive diversity category was used to code subjects and was designated as F/URM/D ( 1 = female, URM, and/or disability) and WRM ( 0 = well-represented male [white or Asian male]). The type of undergraduate institution was included as a covariate in the regression model, since information provided in application materials suggested that the college experience of applicants to the SPIRE program who attended an MSI or primarily undergraduate institution (PUI) seemed to influence the decision to apply to such a program, since they identified strong mentorship by faculty and opportunities for undergraduate research as desired components of their future careers ( 1 = PUI or MSI, $0=$ other institutions, including master's granting or research-intensive institution). The number of publications for each participant was counted and coded. Publications from both graduate and postdoctoral work before the start of their first professional positions were included. Publications that resulted from their postdoctoral research that were accepted but may not have been in print before the start of their career positions were included in this calculation as well ( $1=6$ or more publications, $0=5$ or fewer). The average total number of first-author publications was calculated to be 3.3. Thus, first-author publications were coded as four or more (more than average) in the regression analysis ( $1=4$ or more first-author publications, $0=3$ or fewer). Publications designated as teaching and education research related, such as published curricula, case studies, and formal classroom 
studies, were not included in the analysis. Discipline area of research was coded as $1=$ biology/biomedical sciences/biomedical engineering, $0=$ chemistry/biochemistry. The number of courses taught during the postdoctoral training period and the number of students mentored during the training period were also included in the regression models. Students who were mentored by the postdoctoral scholars were counted if there was direct oversight of the student by the scholars on a research project, either during academic semesters, during the summer, or both. Students who were academic advisees of the postdoctoral scholars or who were informally mentored in other capacities were not counted. Unstandardized coefficient $(B)$, SE of $B$ (SE $B$ ), and exponentiation of the coefficients $(\exp (B))$ are provided in tables. Outcome analyses of interactions between multiple social identities such as white males and URM males and URM females were not performed due to the small sample size, which limited the statistical power and data interpretation. Course evaluation forms were administered at the partner MSIs during the last 2 wk of each course taught by the SPIRE scholars, and results were compiled by Strategic Evaluations. All statistical tests and logistic regression models were performed using SPSS, version 23 (IBM, New York, NY). This study was approved by UNC Chapel Hill Institutional Review Board study 15-2421.

\section{RESULTS}

\section{Broadening Participation for Postdoctoral Trainees}

We hypothesized that a structured training program that includes research, teaching, and professional development supports the career development of a high proportion of URMs and females and results in a range of academic career outcomes for all scholars involved in the program. Although the IRACDA programs are not designed as a postdoctoral experience targeted only for URM participation, a large proportion of URMs apply and are accepted into these programs (Brommer and Eisen, 2006; Hue et al., 2010; Rybarczyk et al., 2011). The demographics of the SPIRE scholars show a nearly twofold greater proportion of female scholars $\left(\chi^{2}=27.51, p<0.05\right)$ and a nearly threefold greater proportion of URM scholars $\left(\chi^{2}=35.92, p<0.05\right)$ compared with a national sample of postdoctoral scholars (Table 1 ). There were no significant differences detected in comparing the frequencies of scholars with disabilities between the two groups (Table 1).

We created two models for logistic regression analysis to determine predictor variables that may explain actual career outcomes of the postdoctoral scholars. Logistic regression analysis was conducted for one model termed "demographic factors" and incorporated the variables of predicted career out-

TABLE 1. Demographics of postdoctoral scholars

\begin{tabular}{lcc}
\hline & $\begin{array}{c}\text { SPIRE } \\
(\boldsymbol{n}=\mathbf{8 1})\end{array}$ & $\begin{array}{c}\text { National data }^{\mathrm{a}} \\
(\boldsymbol{n}=\mathbf{2 1 , 5 0 0 )}\end{array}$ \\
\hline Female & $56(69 \%)$ & $8700(40 \%)$ \\
Male & $25(31 \%)$ & $12,800(60 \%)$ \\
White/Asian & $54(68 \%)$ & $19,200(89 \%)$ \\
URM & $25(32 \%)$ & $2300(11 \%)$ \\
No disability & $76(94 \%)$ & $20,800(97 \%)$ \\
With disability & $5(6 \%)$ & $700(3 \%)$ \\
\hline
\end{tabular}

aNSF, 2016, table 9-22.
TABLE 2. Logistic regression modeling of demographic factors predicting actual career placement in a faculty position composed of both research and teaching $(n=77)$

\begin{tabular}{lrrrc}
\hline & \multicolumn{2}{c}{$\begin{array}{c}\text { Unstandardized } \\
\text { coefficients }\end{array}$} & & Odds ratio (95\% CI) \\
\cline { 2 - 3 } \cline { 5 - 5 } & \multicolumn{1}{c}{$\boldsymbol{B}$} & SE $\boldsymbol{B}$ & & $\operatorname{exp(B)}$ \\
\hline Predicted career & 1.19 & 0.54 & & $3.29(1.15-9.43) *$ \\
Gender (female) & -0.55 & 0.53 & & $0.58(0.21-1.64)$ \\
URM status & 0.89 & 0.51 & & $1.09(0.40-2.96)$ \\
Undergrad institution & -0.37 & 0.53 & & $0.69(0.26-1.87)$ \\
\hline
\end{tabular}

$* p<0.05$.

come, URM identity, gender, and type of undergraduate institution. Analysis indicated that the predicted career outcome was positively correlated with the career outcome of a faculty position that included research and teaching (odds ratio [OR]: 3.29; 95\% confidence interval [CI]: 1.15-9.43; $p<0.05$, Table 2). URM status was positively correlated with career outcome, while gender and type of undergraduate institution attended negatively correlated with the outcome variable but were not significant variables (Table 2). These results suggest that the scholars' intended career outcome, but not demographics or the type undergraduate institution attended, predicts the actual career outcome attained.

A second model termed "productivity factors" was analyzed to determine predictor variables related to productivity in research, teaching, and mentoring that may explain the type of actual career position attained. The variables tested in this model included the number of scientific publications, number of courses taught as a postdoctoral scholar, number of students mentored, and discipline area of research. The results indicated that the total number of publications (OR: 2.75; 95\% CI: $0.97-$ $7.80 ; p=0.058$ ) and four or more first-author publications (OR: 3.57; 95\% CI: 1.12-11.35; $p=0.031$ ) were positive predictors of the actual career outcome. Discipline area of biology/biomedical sciences (OR: 5.27; 95\% CI: 1.11-24.87; $p<0.05$ ) was also a positive and significant predictor of the actual career outcome (Table 3). The number of courses taught and the number of students mentored were also positive variables but were not significant predictors of the outcome variable in the regression model (Table 3).

Because scientific publications are a primary measure of the quality of an applicant for a faculty position, this number was quantified from each of the study participants and aligned with

TABLE 3. Logistic regression modeling of productivity factors predicting actual career placement in a faculty position composed of both research and teaching $(n=77)$

\begin{tabular}{lcccc}
\hline & \multicolumn{2}{c}{$\begin{array}{c}\text { Unstandardized } \\
\text { coefficients }\end{array}$} & & Odds ratio (95\% CI) \\
\cline { 2 - 3 } \cline { 5 - 5 } & $\boldsymbol{B}$ & SE $\boldsymbol{B}$ & & $\exp (\boldsymbol{B})$ \\
\hline Total publications & 1.01 & 0.53 & & $2.75(0.97-7.80)^{*}$ \\
First-author publications & 1.27 & 0.59 & & $3.57(1.12-11.35)^{*}$ \\
Courses & 0.01 & 0.23 & & $1.10(0.70-1.74)$ \\
Students mentored & 0.13 & 0.11 & & $1.14(0.91-1.43)$ \\
Discipline & 1.66 & 0.79 & & $5.27(1.11-24.87)^{*}$ \\
\hline
\end{tabular}

${ }^{*} p<0.05$. 


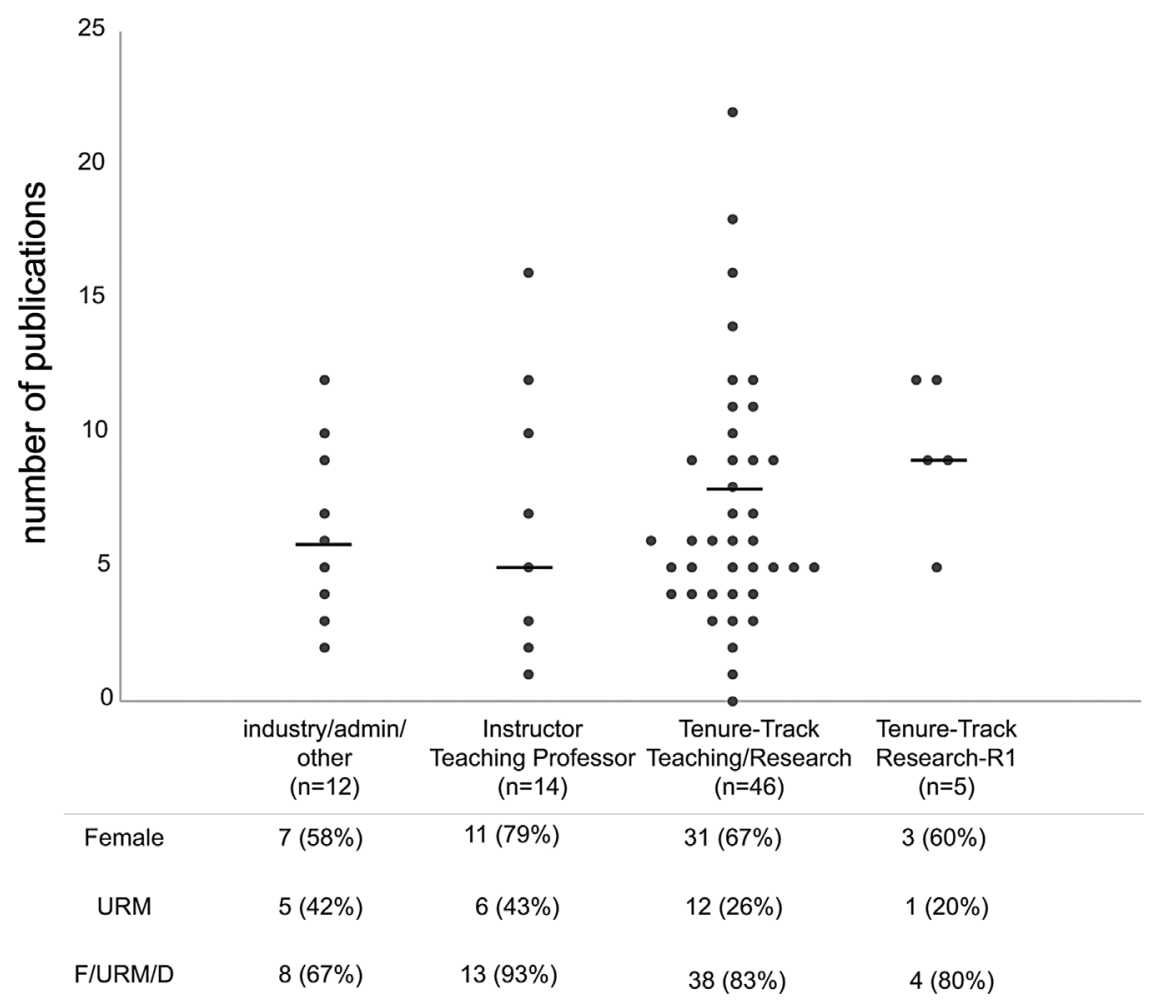

FIGURE 1. Distribution of the number of publications as a function of type of career position. Mean indicated by horizontal bar. F/URM/D, female, underrepresented racial minority, and/or disability status. Comparison of number of publications between non-tenure-track outcome and tenure-track outcomes approached significance (ANOVA, $F=3.25, p=0.075$ ).

the actual position attained after completing the program. Results indicate that the number of publications varied depending on the type of academic position obtained (Figure 1). Scholars who attained tenure-track faculty positions had a greater number of publications (mean $=7.5$, median $=6$ ) compared with scholars who transitioned into non-tenure-track or nonacademic positions (mean $=5.6$, median $=5$ ), which approached significance (analysis of variance [ANOVA], $F=3.25, p=$ 0.075). This result is not surprising, since most tenure-track positions require evidence of research productivity at the time of application with the expectation of continue publishing as faculty.

We investigated the diversity composition of the different career outcomes of SPIRE scholars (Figure 1). For clarity, the dichotomous comparisons (i.e., males, non-URMs, and WRM) are not shown. For SPIRE scholars who attained academic faculty positions (instructors/teaching professors plus tenure-track faculty in positions that balance teaching/research plus tenure-track faculty at R1 institutions), $69 \%$ were female (45 out of 65 ) $29 \%$ were URM (19 out of 65 ), and $85 \%$ (55 out of 65 ) were categorized in the more inclusive category of F/URM/D (Figure 1). Only four SPIRE scholars (5\%) completed the program and entered into a second postdoctoral experience in a lab different from the one they participated in during the SPIRE postdoctoral fellowship, indicating that the SPIRE postdoctoral experience was sufficient to prepare a majority of the scholars to transition directly into desired academic faculty positions.
Resistance to Changes in Labor Market An important step in obtaining a faculty position is presenting one's experience and qualifications in the job application process. The quality of the job application materials, training experience, productivity of the applicant, and alignment with the posted position all play roles in attaining an interview and subsequent job offer. The number of job applications submitted by postdoctoral scholars was used as a measure of their application behavior for academic positions. The number of job applications submitted for academic positions between 2002 and 2015 was reported by a subset of the scholars who completed the program (41 of 77 scholars, 53\%, 29 female, 11 URM, 3 disability). Two scholars reported the number of job applications submitted as greater than 25 and thus were treated as outliers and not included in the analysis. Given the alignment of the training components provided by the SPIRE program with the expectations of an academic faculty position, we hypothesized that the scholars in the program would not change their academic job application behavior as a result of the 2008 economic downturn or ability to attain academic faculty positions. The number of job applications submitted were analyzed based on whether the applicants attained career positions before 2008 or after 2008. Overall, there were no significant differences in the mean number of applications submitted pre2008 (5.5 \pm 1 , range $1-15)$ or post-2008 (6 \pm 0.85 , range $1-20$ ) (ANOVA, $F=0.14, p=0.71$ ). An analysis of the number of applications submitted by scholars pre-2008 showed that females submitted slightly more applications than males, while URMs submitted slightly fewer applications than nonURMs, but these differences were not significant (ANOVA, n.s.; Figure 2A). Similar patterns in job application behavior were seen post-2008, but again, no significant differences were found in the number of applications submitted post-2008 based on gender, URM status, or the inclusive category F/ URM/D (ANOVA, n.s.; Figure 2A). Together, these data suggest that there were no detectable differences between the numbers of job applications submitted by postdocs pre- and post-2008, and thus the scholars exhibited similar behaviors in applying for academic positions regardless of demographics in the context of the 2008 economic downturn.

Overall, the proportion of scholars with known career outcomes $(n=77)$ who obtained tenure-track faculty and academic track positions before 2008 was slightly higher at $80 \%$ than post-2008 at 65\%; however, this difference was not significant $\left(\chi^{2}=2.31, p=0.13\right.$; Figure $\left.2 B\right)$. Thus, data show that postdoctoral scholars completing the SPIRE program continue to attain faculty positions at a higher rate compared with $\mathrm{PhD}$ holders with up to 5 yr since degree completion (19.4\%; NSF, 2016; Figure 2B). Additionally, employment data show that 

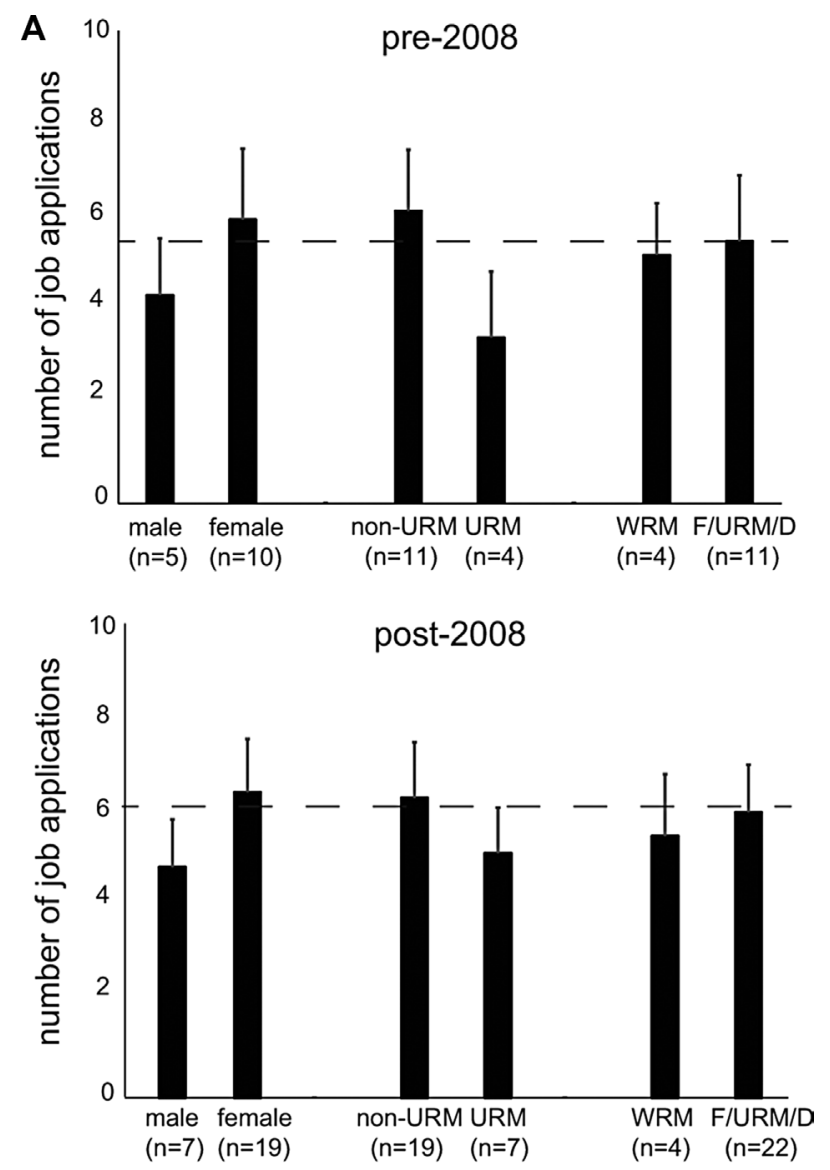

B

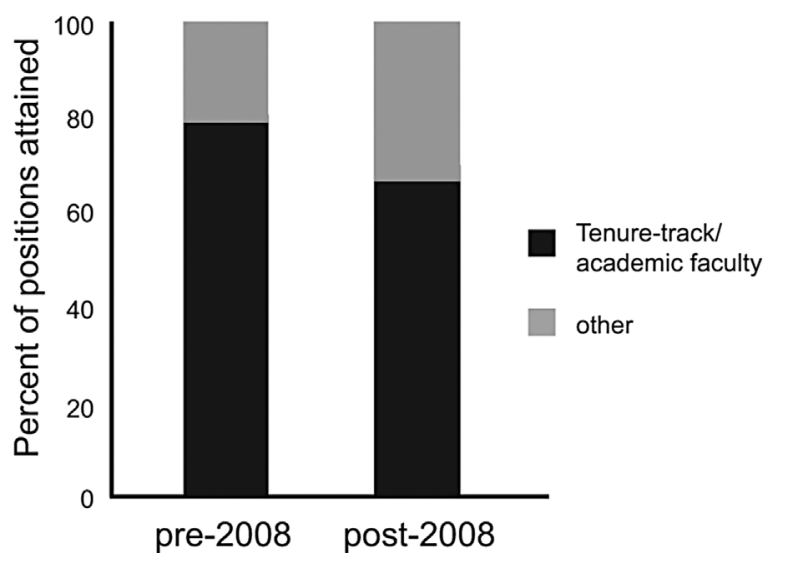

FIGURE 2. Analysis of number of job applications submitted (A) and percent of positions attained (B) pre- and post-2008 economic downturn. (A) Pre-2008, $n=15$; post-2008, $n=26$. Dashed line represents mean number of publications. Error bars indicate SEM. Gender, URM status, and WRM vs. an inclusive diversity status (F/URM/D) were used as categories for comparison. (B) Career position outcomes: $\boldsymbol{n}=35$ scholars in pre-2008 group; $n=42$ scholars in post-2008 group. Other = industry, academic administrative positions, and non-science employment. Difference in the percentage of positions obtained by type between pre- and post-2008 was not significant $\left(\chi^{2}=2.31, p=0.13\right)$. eight SPIRE scholars (10\%) completed the program and entered into visiting faculty positions for a duration of 1-4 yr and then transitioned into permanent tenure-track positions. Six scholars (8\%, all female) attained employment at community colleges in either part-time or full-time positions. Taken together, the data show that postdocs apply for and attain academic positions at no different rates than before the 2008 economic downturn.

\section{Key Factors for Successful First-Year Faculty}

Quality training experiences and a productive research program continue to be important factors for transition to faculty positions in academia. Postdoctoral scholars apply for and are offered faculty positions based on these merits along with their fit with the needs of hiring institutions. We hypothesized that a combination of research training and the opportunity to gain additional academic skills during postdoctoral training would prepare these junior faculty candidates for the responsibilities of a faculty position and result in continued contributions to broaden participation in STEM fields.

Ten alumni of the SPIRE program were interviewed to determine which aspects of the training experience were most valuable to them in their current faculty positions. Interviews were conducted 12-18 mo after the alumni exited the program to ensure that they had completed at least one full academic year in their respective faculty positions. The alumni held academic faculty positions at research universities, liberal arts universities, community colleges, and a science magnet high school. Scholars' teaching responsibilities were in chemistry, biology, microbiology, marine science, ecology, and biopsychology/neuroscience. The time devoted to teaching and research ranged from $20 \%$ teaching: $80 \%$ research to $100 \%$ teaching. Seven of the 10 alumni were currently engaged in research; two had plans to start research; and one did not have the option to engage in research.

\section{Balancing Faculty Responsibilities}

All 10 alumni felt that, overall, they were prepared for their new positions based on their postdoctoral training experience. Alumni reported feeling at ease with teaching, transitioning into their new faculty roles, and anticipating the balance of multiple demands on their time:

"Well teaching is definitely a breeze because of all the planning, preparing syllabus and communicating with students, teaching is just going really well, no issue at all. Research, again, I also carried over a lot of what I was doing in the SPIRE Program into my position here at [my institution] so that helps a lot. It means that I'm kind of ahead because I was in the midst of a variety of different projects and it really helped in terms of just making sure that I hit the ground running and moving forward." (Male, URM)

"I would say I definitely feel prepared. People keep asking me, 'Oh, has the transition been hard?' And I would say 'No, it's not really been hard.' ... I know that next semester I'll have a heavier teaching load and be doing more research. But I feel like I can handle that, I've done it before." (Female, non-URM) 


\section{Value of Pedagogical Training and Classroom Teaching Experience}

As part of the preparation for teaching during the postdoctoral fellowship, alumni of the program had taken part in a workshop series focused on pedagogical skills and gained teaching experience at the partner universities. The workshop series was a key component that alumni identified as most helpful for preparing them for their new positions:

"I've had several students comment and they're shocked and surprised to find out that I've only at this point been here, this is my second year here, because I have the confidence of a well-seasoned professor. And I think the teaching experience and the workshops in SPIRE helped me with that, so the students don't realize how new at this game I am." (Female, non-URM)

"I feel like I have an advantage in terms of teaching just because, like I said, all the training that I got in SPIRE really allowed that to be a relatively easy and straightforward task. Research, I think it's comparable to what I see when I'm with other faculty in the same position at the same point in their careers." (Male, URM)

\section{Competitive Advantage on the Job Market}

Alumni were certain that they had benefited from the SPIRE program with regard to being competitive in the job market. A majority of the alumni noted that skills and experience gained from participation in SPIRE had positioned them to be hired into their current positions:

"Everyone that I interviewed with ... when I spoke about SPIRE, was just like 'Wow, here's someone who is actually trained in undergraduate teaching."' (Female, non-URM)

"So getting to teach at [the partner university] the two semesters-if it wasn't for that ... I wouldn't have this job and my hiring committee told me as much basically. But it wasn't just the teaching part, though, because they get a lot of people that have taught, but it was the training that went along with it and that's what got people so excited and what was so helpful ... So being able to hit the ground running with that [training] is very, very highly valued." (Male, non-URM)

\section{Unanticipated Challenges in Career Position}

While the majority of alumni felt very well-prepared for balancing teaching responsibilities with research, several themes emerged about challenges in their first career position:

"Going into [the position] I can say I definitely felt prepared and then I got the first semester. And the first semester was a full teaching load and I was teaching three lectures and four labs. And each lecture was a different course ... So in that sense [I] probably [was] not [adequately prepared] because I never taught two classes at the same time." (Female, non-URM)

Several alumni spoke of being challenged by unanticipated demands on their time-particularly regarding interactions with students but also unexpected obligations for university service:
"[Something] that surprised me was how much time and attention is devoted just to student relationships. Students drop by and you think that you've set aside this hour to work on your lecture and then five students stop by your office ... but student relationships is something I wasn't prepared for as much as I thought I was going to be." (Female, non-URM)

"Probably the biggest challenges are-and it really started to hit the second year here as opposed to the first-but balancing course work with other obligations ... We have a big emphasis on [institutional service] here and it wasn't something I was expecting to spend a lot of time on, in addition to the research and the teaching." (Female, non-URM)

"I'm always trying to adjust and adapt and figure out what's the best way to get the students involved when you have a maximum of 110 students ... So I have to say that just trying to deal with a larger class in terms of trying to get the concepts across and implementing the active learning strategies is the most challenging thing as it relates to the instruction for me." (Male, URM)

Even though most alumni had successfully acquired start-up funding for their labs, a few alumni expressed concerns about finding continued funding for their lab research:

"For me it's definitely [a challenge] accessing funding and I'm working really hard and I feel like I'm doing a good job in showing that I get my grants submitted. I think I'll be very excited once I receive that first major grant ... And I think if I get through that I'll pretty much have everything covered; teaching, research, and I think everything will pretty much go smoothly from there." (Male, URM)

Collectively, these responses indicate specific aspects of the training program that prepared alumni for the rigors of their first academic positions and revealed challenges associated with transition into faculty positions.

\section{Impacts on Undergraduate Education to Broaden Participation in STEM}

Scholars in the SPIRE program interact with a diverse group of undergraduate students at the partner campuses, including students from different socioeconomic backgrounds, first-generation college students, returning veterans, and students with disabilities. Contributions to broadening participation in STEM at the undergraduate level include courses taught by the SPIRE postdoctoral scholars as instructors of record, direct mentoring of undergraduate students on research projects during both academic semesters at the MSIs, and mentoring during the summer in laboratories at the research-intensive institution. Data show that 71 out of 77 scholars (92.2\%) mentored students on research projects during their fellowship (median number of students mentored $=3$, range $=1-18$ ). The proportion of students mentored coming from the program's partner institutions was 39\% $(n=103)$, with $42 \%(n=111)$ drawn from the primary research institution and 18\% $(n=48)$ drawn from summer research programs administered at the primary research institution (Table 4). The scholars mentored undergraduate students from partner institutions primarily during summer research programs. In several instances, to maintain continuity and productivity, scholars established a research 
TABLE 4. Students mentored in research by SPIRE scholars $(n=71)$, 2000-2015

\begin{tabular}{lcc}
\hline & Number of students $(\boldsymbol{n}=\mathbf{2 6 2})$ & Percent \\
\hline Partner institution & 103 & 39 \\
Research institution & 111 & 42 \\
Other & 48 & 18 \\
\hline
\end{tabular}

project with an undergraduate student during the summer and continued mentoring the student at the partner institution during the academic semesters.

The SPIRE postdoctoral scholars taught introductory-level courses, specialized elective courses, and courses that integrated research-based approaches, including components of their own research projects. The scholars worked with faculty teaching mentors at the partner institutions to ensure that courses aligned with departmental policies, standards, and overall curricula. Scholars also introduced new laboratory exercises and offered upper-level courses that were not otherwise available to students. Overall, as instructors of record at the program's partner campuses, SPIRE scholars taught a total of 177 courses involving more than 3000 students since 2002. SPIRE scholars taught high proportions of female students (66\%) and URMs (80.4\%) in introductory courses (Table 5). In upper-division courses, SPIRE scholars taught even higher percentages of female students (75.5\%) and URMs (84\%) (Table 5). These data suggest that the SPIRE program provides opportunities for postdoctoral scholars to contribute to the education of diverse undergraduate student populations at multiple institutions. Evidence of teaching effectiveness were most prominent from student evaluations of the courses, with positive impacts on students' perception of developing their critical thinking skills, motivation to pursue a career in science, pursue graduate studies, and enroll in additional science courses (Table 6).

\section{Continued Efforts to Broaden Participation in First Academic Position}

Seventy-one of the 77 alumni (92\%) held academic positions. An important demonstration of long-term commitment to broadening participation is the attainment of faculty positions at MSIs, institutions that have a historic mission and commitment to serving students from diverse backgrounds. Of the 71 alumni, nine (12\%) transitioned into faculty positions at MSIs, many of which are or were part of the SPIRE program partnership. The 71 alumni who held academic positions were asked to report on their continued efforts to broaden participation in their first academic position. Forty-eight responded to this request (34 [71\%] female and 16 [33\%] URM; Table 7). This is a representative sample of the total SPIRE alumni group based on demographics (Table 1). Additionally, 40 (83\%) of the scholars reported that they continue to broaden participation through mentoring and advising URM students in their current roles (Table 7). Other ways that the scholars supported diversity as

TABLE 5. Demographics of students taught by SPIRE scholars $(n=77)$

\begin{tabular}{|c|c|c|c|c|c|}
\hline & & \multicolumn{2}{|c|}{ Intro/general courses } & \multicolumn{2}{|c|}{ Upper-level courses } \\
\hline & & Number of students & Percent & Number of students & Percent \\
\hline \multirow[t]{2}{*}{ Gender } & Male & 517 & 33.6 & 361 & 24.8 \\
\hline & Female & 1023 & 66.4 & 1092 & 75.2 \\
\hline \multirow[t]{7}{*}{ Race/ethnicity } & Asian & 31 & 2.1 & 34 & 2.4 \\
\hline & Black or African American & 1054 & 69.9 & 1066 & 75.5 \\
\hline & Hispanic or Latino & 26 & 1.7 & 50 & 3.5 \\
\hline & Native American & 91 & 6.0 & 33 & 2.3 \\
\hline & Native Hawaiian or Other Pacific Islander & 8 & 0.5 & 7 & 0.5 \\
\hline & Multiracial & 35 & 2.3 & 30 & 2.1 \\
\hline & White & 262 & 17.4 & 191 & 13.5 \\
\hline
\end{tabular}

Shaded rows indicate URM status.

TABLE 6. Summary of students' course evaluations

\begin{tabular}{|c|c|c|c|}
\hline & $\begin{array}{l}\text { Introductory-level courses } \\
\qquad(n=1561)\end{array}$ & $\begin{array}{l}\text { Upper-level courses } \\
\quad(n=1468)\end{array}$ & $\begin{array}{l}\text { Combined total } \\
\quad(n=3029)\end{array}$ \\
\hline $\begin{array}{l}\text { This course taught me what I wanted to know about the subject } \\
\text { matter. }\end{array}$ & $4.12 \pm 0.949$ & $4.16 \pm 0.922$ & $4.13 \pm 0.936$ \\
\hline $\begin{array}{l}\text { This course challenged me to think critically and in new ways } \\
\text { about the subject matter. }\end{array}$ & $4.26 \pm 0.866$ & $4.36 \pm 0.836$ & $4.31 \pm 0.852$ \\
\hline $\begin{array}{l}\text { Taking this course has motivated me to pursue a career in the } \\
\text { biological sciences. }\end{array}$ & $3.31 \pm 1.412$ & $3.78 \pm 1.201$ & $3.54 \pm 1.333$ \\
\hline $\begin{array}{l}\text { Taking this course has motivated me to pursue additional courses } \\
\text { in this field. }\end{array}$ & $3.35 \pm 1.379$ & $3.67 \pm 1.227$ & $3.51 \pm 1.316$ \\
\hline $\begin{array}{l}\text { This course helped motivate me to attend graduate/professional } \\
\text { school after I complete my undergraduate degree. }\end{array}$ & $3.71 \pm 1.229$ & $3.82 \pm 1.183$ & $3.77 \pm 1.203$ \\
\hline
\end{tabular}

A higher mean response indicates higher level of agreement: "strongly disagree" $=1$; "strongly agree" $=5$. Historic mean \pm STD is an aggregate mean of all student responses received across courses taught Fall 2002-2014. 
TABLE 7. Scholars' contributions to broadening participation in academic positions

\begin{tabular}{|c|c|}
\hline Diversity-related categories and examples & $\begin{array}{c}\text { Number }(\%) \\
(n=48)\end{array}$ \\
\hline $\begin{array}{l}\text { Mentoring and advising URM students } \\
\text { Direct involvement with students in lab } \\
\text { Academic and career advising } \\
\text { Advising first-generation student groups }\end{array}$ & $40(83)$ \\
\hline $\begin{array}{l}\text { Serving on diversity-related committees } \\
\text { Serve on diversity committees at institution } \\
\text { and national scientific organization } \\
\text { Serve on advisory boards }\end{array}$ & $19(40)$ \\
\hline $\begin{array}{l}\text { Submitting proposals for research and program funding } \\
\text { Awarded funding for equipment at MSIs } \\
\text { Submitted grants for diversity programming } \\
\text { Science enrichment grants }\end{array}$ & $18(38)$ \\
\hline $\begin{array}{l}\text { Engaging in science outreach } \\
\text { Integrate service-learning pedagogy into courses } \\
\text { Outreach with community-learning initiatives }\end{array}$ & $16(33)$ \\
\hline $\begin{array}{l}\text { Administering programs } \\
\text { Administer NSF- and NIH-funded training programs } \\
\text { Administer summer research programs }\end{array}$ & 9 (19) \\
\hline
\end{tabular}

faculty were through serving on diversity committees both at their current institution and nationally (38\%), writing proposals for funding opportunities (36\%), science outreach activities (32\%), and creating and administering programs that supported the training of URM students (19\%; Table 7). These results indicate that the SPIRE scholars, regardless of gender or URM status, maintained supportive, longitudinal commitments to broadening participation in the sciences.

\section{DISCUSSION}

The postdoctoral stage is a critical time for scientists' career development as a transition from trainee to many different career paths. This study of postdoctoral scholars was done to elucidate factors associated with trainees' transition into academic faculty positions and impacts on broadening participation and workforce diversity. Data collected in this study provide evidence that supports the value of a postdoctoral training experience that balances research, teaching, and professional development. The postdoctoral scholars in this study gained their research experience at a research-intensive university, while their teaching experience was gained through a partnership with several universities that serve underrepresented groups. Thus, the postdoctoral experience provided opportunities for developing into an independent researcher, similar to a traditional postdoctoral experience, and provided additional opportunities to support broadening participation of underrepresented students in the sciences at other institutions.

\section{Predictors of Career Outcomes}

The data in this study support previous findings indicating that the factors predicting a successful transition into faculty positions are 1) the postdoctoral scholars' intended career track when they enter their postdoctoral position, 2) the total number of scientific publications, and 3) the number of first-author scientific publications they produced during their graduate and postdoctoral training. Previous research indicates that the decisions postdocs make about their career trajectories midgraduate studies often predict their subsequent success as faculty within STEM disciplines (Fuhrmann et al., 2011; Gibbs et al., 2015). When targeting future training opportunities, aspects identified by social cognitive career theory play a role in how STEM trainees, at earlier stages, identify their own next steps in their professional development and career progression (Byars-Winston et al., 2010, 2011).

Two of the factors used to select applicants to the SPIRE program were 1) the applicants' commitment to an academic career that balances both teaching and research and 2) their commitment to support diversity in STEM disciplines. Additional factors that play a role in the selection process are the applicants' commitment to 1) expanding their own research productivity and 2) improving undergraduate instruction in STEM courses, specifically by engaging students in research inquiry. Therefore, $100 \%$ of the participants in the SPIRE sample revealed these characteristics when they entered the program, which makes our sample unique. In contrast, previous studies measured graduate students' interest in faculty research careers at much lower rates of 33\% for students in the biological sciences and $21 \%$ for students in chemistry (Sauermann and Roach, 2012). The SPIRE sample group is also different from other studies that either capture a more heterogeneous sample of STEM trainees or assess their career choices at an earlier stage of career development (Gibbs et al., 2014).

When seeking academic positions, it is helpful to know more about the qualifications needed to attain different types of faculty positions. Research productivity, as measured by research publications, was a significant predictor of outcome expectations for faculty positions in this study and represents a primary factor important for assessing candidates for faculty positions. The current study used the full publication record of the scholars and the number of first-author publications to assess research productivity. Although search committees might place more weight and value on first-author publications, the full publication record is also considered important on an applicant's CV as part of a job application and reveals more information about collaborators, areas of research, and the range of journal articles published.

Applicants to the SPIRE program usually state their interest in supporting undergraduate education as a way to contribute to and enhance diversity, based on either 1) their own experiences at PUIs or MSIs or 2) positive, mentored experiences at other types of institutions throughout their training. Although the type of undergraduate institution the SPIRE scholars attended did not significantly predict increased odds of attaining a faculty position (Table 2), it is likely that their mentored experiences and interactions with faculty as undergraduate students would have an effect on the postdocs' career outcomes and specific responsibilities as faculty themselves. Data from the current study indicated that the number of courses taught and number of students mentored were important predictors of whether individuals attained an academic position, regardless of the specific type of position attained. Previous data support the value of teaching experience and indicate that the opportunity to be the instructor of record distinguished postdoctoral scholars seeking academic positions (Rybarczyk et al., 2011). It is likely that postdocs with substantial teaching experience would deliver a more effective teaching demonstration as part 
of the interview process for faculty positions and provides additional criteria for selection of optimal candidates for these available faculty positions (Smith et al., 2013).

\section{Effects of the Economic Downturn and Transitioning into Academic Positions}

Postdoctoral scholars in the sciences face limiting opportunities for academic faculty employment and thus increased competition for these positions (Garrison et al., 2016). A much lower percentage of SPIRE scholars sought a second postdoctoral experience (5\%, 4 out of 77 ) as compared with data from a previous report stating that $30 \%$ of postdoctoral trainees had at least two postdoctoral experiences (Powell, 2012), suggesting that additional time and preparation for a faculty position was not necessary for successful transition through the academic career track. Data indicate that postdocs within the SPIRE program were more likely to transition into faculty positions when compared with national data sets. In this study, scholars attained academic faculty positions at similarly high rates regardless of the 2008 economic downturn, and when pre- and post-2008 career placement data were compared, it was not found that scholars sought nonacademic positions at differential rates (Figure 2). Although the postdoctoral scholars submitted more job applications after 2008, taken together, these data suggest that the quality of the postdoctoral scholars' qualifications in research, teaching, service, and mentoring experience align with expectations for faculty candidates.

\section{Insights about Broadening Participation}

Career outcomes reported from our study are particularly striking in the context of workforce diversity, since the sample group included a larger percentage of female and URM postdoctoral scholars than the national sample. Female SPIRE scholars obtained academic faculty positions, inclusive of instructors/ lecturers through tenure-track faculty, at a higher rate (45 out of $65,69 \%$; Figure 1) when compared with a national sample (34\%; table 9-22 in NSF, 2016) and when compared with female assistant professors in the life sciences (Ceci et al., 2014). The proportion of URMs from the SPIRE program who attained faculty positions (19 out of 65, 29\%; Figure 1) is threefold greater compared with a national sample (9.5\%; table 9-22 in NSF, 2016). These data suggest that the SPIRE program supports the transition of females and URMs into faculty positions to a greater extent than demonstrated in the national trends. This is in contrast to previous data indicating that women and URMs are less interested in faculty careers, particularly at research universities (Gibbs et al., 2015). In this context, it should be noted that the current study defined career outcome broadly, as a balance of research and teaching in a faculty position, versus the traditional benchmark of a research-only career.

\section{Commitment to Diversity}

Through their teaching experience, the postdoctoral scholars interacted with a large number of URM students and enriched the teaching environments at these partner universities by enhancing introductory-level courses, creating and delivering upper-level and inquiry-based courses, and broadening students' participation in research. Data that describe the activities of scholars now working in academia in permanent positions (Table 7) demonstrate that alumni from the program continue to support diversity in undergraduate education and contribute to broadening participation through a wide range of activities such as mentoring URM students, participating on diversity-related committees, and submitting proposals for funding that supports URM training initiatives. Such evidence of a commitment to supporting diversity and broadening participation that bridges the trainee-to-career position is largely undocumented in the career development literature and thus is an important outcome from the study.

\section{Limitations of the Study}

This study had several limitations. First, the participants in this study were drawn from one program, thereby limiting the ability to generalize the results for comparison with other programs or individuals. Because this is a retrospective, longitudinal study, there were no direct measurements related to self-efficacy in career decision making beyond the stated career goals by the participants at the start of the program, unlike the use of standardized self-efficacy measures in other studies (Byars-Winston et al., 2010, 2011). Additionally, some analyses, such as the postprogram interviews, gathered qualitative data from a subset of the total group of postdoctoral scholars in the program and thus may not represent all of the perspectives from the total group of subjects, limiting the diversity of perspectives presented.

There are likely to be a multitude of factors that influence a postdoctoral scholar's perceived self-efficacy to be successful in different types of academic positions. For example, a common sentiment expressed by scholars who did not pursue tenure-track faculty positions at research-intensive institutions is concern about the expectation of writing grants to fund independent research programs in resource-limited environments and the high level of competition for federal grant funding. Also, we observed that several scholars in the SPIRE program realized that they could have a greater impact on undergraduate education through classroom teaching and mentoring students. Thus, several SPIRE scholars transitioned to positions that allowed them to emphasize student mentoring. Other factors not measured in this study that could have influenced the career outcomes of the postdoctoral scholars that have been documented in other studies were the quality of mentorship provided by research mentors (Scaffidi and Berman, 2011), self-efficacy of establishing and translating research projects to different types of institutions, geographically restricted job searches, and challenges of balancing family and spousal career considerations (Perry et al., 2000; Anders, 2004); however, others have shown that these factors do not explain all of the variance in career interest (Gibbs et al., 2015).

\section{SUMMARY}

Factors that affect the type of position attained after postdoctoral training are countless and involve academic job market considerations as well as personal and professional values and goals. Job market factors include availability of positions at the time of completion of the postdoctoral training period, match of institutional needs/values with personal and professional goals, and fit and congeniality with departmental colleagues. Personal considerations of transitioning into an academic faculty position include factors such as perceived balance of work and family, spousal/partner work location, and opportunities for 
growth. According to alumni of the program, the aspects that had the greatest impact on their current position were 1) the structured training in both research and teaching and 2) interactions with a community of scholars who have similar professional goals. These aspects of the postdoctoral experience are similar to those found in previous studies of alumni from another structured postdoctoral program (Faupel-Badger et al., 2015).

Thus, structured training programs should continue to define expected career outcomes and align training interventions to support postdoctoral skill and career development. The results of this study provide evidence for training opportunities that enhance transition into academic faculty positions. Results support efforts for reforming STEM training programs to define expected skills development and refine program interventions to support the development of these skills. In the context of scientific training programs, it is important to broaden and redefine measures of success and expected career outcomes. These outcomes should include different ratios of research, teaching, mentoring, service, and opportunities to contribute to broadening participation in STEM. For a postdoctoral scholar exploring career positions beyond the traditional research-only tenure-track faculty option, finding the right match with a desired career position will ultimately lead to more career satisfaction.

\section{ACKNOWLEDGMENTS}

This work was supported by a NIGMS grant (GMK12000678). Special thanks to Rosemary Russo for statistical consultation.

\section{REFERENCES}

Anders S (2004). Why the academic pipeline leaks: fewer men than women perceive barriers to becoming professors. Sex Roles 51, 511-521.

Austin AE, Campa H, Pfund C, Gillian-Daniel DL, Mathieu R, Stoddart J (2009). Preparing STEM doctoral students for future faculty careers. New Dir Teach Learn 2009, 83-95.

Brommer CL, Eisen A (2006). FIRST: a model for increasing quality minority participation in the sciences from the undergraduate to the professoriate level. J Women Minor Sci Eng 12, 35-46.

Building Engineering \& Science Talent (2003). The Quiet Crisis: Falling Short in Producing American Scientific and Technical Talent, San Diego, CA.

Byars-Winston A, Estrada Y, Howard C, Davis D, Zalapa J (2010). Influence of social cognitive and ethnic variables on academic goals of underrepresented students in science and engineering: a multiple-groups analysis. J Couns Psychol 57, 205.

Byars-Winston A, Gutierrez B, Topp S, Carnes M (2011). Integrating theory and practice to increase scientific workforce diversity: a framework for career development in graduate research training. CBE Life Sci Educ 10, 357-367.

Ceci SJ, Ginther DK, Kahn S, Williams WM (2014). Women in academic science: a changing landscape. Psychol Sci Public Interest 15, 75-141.

Cyranoski D, Gilbert N, Ledford H, Nayar A, Yahia M (2011). The Ph.D. factory. Nature 472, 276-279.

Ebert-May D, Derting TL, Henkel TP, Middlemis Maher J, Momsen JL, Arnold B, Passmore HA (2015). Breaking the cycle: future faculty begin teaching with learner-centered strategies after professional development. CBE Life Sci Educ 14, ar22.

Faupel-Badger JM, Raue K, Nelson DE, Tsakraklides S (2015). Alumni perspectives on career preparation during a postdoctoral training program: a qualitative study. CBE Life Sci Educ 14, ar1.
Fuhrmann CN, Halme DG, O'Sullivan PS, Lindstaedt B (2011). Improving graduate education to support a branching career pipeline: recommendations based on a survey of doctoral students in the basic biomedical sciences. CBE Life Sci Educ 10, 239-249.

Garriott PO, Flores LY, Martens MP (2013). Predicting the math/science career goals of low-income prospective first-generation college students. J Couns Psychol 60, 200-209.

Garrison HH, Justement LB, Gerbi SA (2016). Biomedical science postdocs: an end to the era of expansion. FASEB J 30,1-4.

Gibbs KD, Griffin KA (2013). What do I want to be with my PhD? The roles of personal values and structural dynamics in shaping the career interests of recent biomedical science PhD graduates. CBE Life Sci Educ 12, 711-723.

Gibbs KD, McGready J, Bennett JC, Griffin KA (2014). Biomedical science Ph.D. Career interest patterns by race/ethnicity and gender. PLoS One 9 e114736.

Gibbs KD, McGready J, Griffin K (2015). Career development among American biomedical postdocs. CBE Life Sci Educ 14, ar44.

Holtzclaw JD, Morris LG, Pyatt R, Giver CS, Hoey J, Haynes JK, Gunn RB, Eaton D, Eisen A (2005). FIRST: a model for developing new science faculty. J College Sci Teach 34, 24-29

Hue G, Sales J, Comeau D, Lynn DG, Eisen A (2010). The American science pipeline: sustaining innovation in a time of economic crisis. CBE Life Sci Educ 9, 431-434

Knapp LG, Kelly-Reid JE, Ginder SA (2010). Employees in Postsecondary Institutions, Fall 2009, and Salaries of Full-Time Instructional Staff, 200910, Jessup, MD: National Center for Education Statistics.

Lent RW, Brown SD, Hackett G (1994). Toward a unifying social cognitive theory of career and academic interest, choice, and performance. $J$ Vocat Behav 45, 79-122.

McAlpine L, Emmioglu E (2015). Navigating careers: perceptions of sciences doctoral students, post-PhD researchers and pre-tenure academics. Stud High Educ 40, 1-16.

National Institute of General Medical Science (2011). Investing in the Future: The National Institute of General Medical Sciences Strategic Plan for Biomedical and Behavioral Research Training, Washington, DC.

National Science Board (2007). A National Action Plan for Addressing the Critical Needs of the U.S. Science, Technology, Engineering, and Mathematics Education System, Arlington, VA: National Science Foundation.

National Science and Technology Council (2000). Ensuring a Strong U.S. Scientific, Technical, and Engineering Workforce in the 21st Century, Washington, DC.

National Science Foundation (NSF) (2006). Characteristics of Doctoral Scientists and Engineers in the United States: 2003, Arlington, VA

NSF (2016). Women, Minorities, and Persons with Disabilities in Science and Engineering: 2016, Arlington, VA.

Perry R, Clifton R, Menec V, Struthers CW, Menges R (2000). Faculty in transition: a longitudinal analysis of perceived control and type of institution in the research productivity of newly hired faculty. Res High Educ 41, 165-194.

Polka JK, Krukenberg KA, McDowell GS (2015). A call for transparency in tracking student and postdoc career outcomes. Mol Biol Cell 26, 14131415 .

Powell K (2012). The postdoc experience: high expectations, grounded in reality. In: ScienceCareers, Washington, DC: AAAS/Science Custom Publishing Office, 992-996. http://sciencecareers.sciencemag.org.

Powell K (2015). The future of the postdoc. Nature 520, 144-147.

Rybarczyk B, Lerea L, Lund PK, Whittington D, Dykstra L (2011). Postdoctoral training aligned with the academic professoriate. BioScience 61, 699-705

Sauermann H, Roach M (2012). Science Ph.D. career preferences: levels, changes, and advisor encouragement. PLoS One 7, e36307.

Scaffidi A, Berman J (2011). A positive postdoctoral experience is related to quality supervision and career mentoring, collaborations, networking and a nurturing research environment. High Educ 62, 685-698.

Smith MK, Wenderoth MP, Tyler M (2013). The teaching demonstration: what faculty expect and how to prepare for this aspect of the job interview. CBE Life Sci Educ 12, 12-18. 